\title{
Endodontic Management of a Mandibular First Molar with Radix Entomolaris- A Case Report
}

\author{
Diana John ${ }^{1}$, Ramesh Kumar M. ${ }^{2}$, Jayasree S. ${ }^{3}$, Nadira K. Rahman ${ }^{4}$, \\ Gokulraj R. ${ }^{5}$, M. AbduRahman T.V. ${ }^{6}$ \\ 1,2,3,4,5,6 Department Of Conservative Dentistry \&Endodontics, Govt. Dental College, Kozhikode, India
}

\begin{abstract}
The primary objective of endodontic treatment is the elimination of microorganisms from the infected root canal and the prevention of subsequent reinfection. This is mainly achieved by a thorough chemomechanical preparation of the root canal, followed by a three-dimensional filling with a fluid tight seal.An inadequacy in the implementation of any of these steps may occur due to atypical tooth morphology. The endodontic treatment of a mandibular molar with aberrant canal configuration can be diagnostically and technically challenging.

Radix Entomolaris (RE) is one such aberration where an extra root is present on the distolingual aspect of mandibular first molar (molar with 3 roots). This article presents a case report of mandibular first molar with an extra distal root and four root canals.
\end{abstract}

Keywords: Anatomical variations, Disto lingual root, Mandibular first molar, Radix Entomolaris

\section{Introduction}

The prevention or healing of endodontic pathology depends on a thorough chemo-mechanicalcleansing and shaping of the root canals before the placement of a dense root canal fillingwith a hermetic seal. An awareness and understanding of the presence of unusual rootcanal morphology can thus contribute to the successful outcome of root canal treatment. (1)Knowledge of the most common anatomical characteristics and their possible variations is fundamental because non-treatment of even one canal can lead to endodontic treatment failure.

The majority of first and second mandibular molars are two rooted with two mesial and one distal canal $(3,4)$. A major variant in this group is the mandibular first molar which has three roots. This variation in the number of roots is called Radix Entomolaris (RE), first mentioned in the literature by Carabelli.

The presence of a separate RE in the first mandibular molar isassociated with certain ethnic groups. In African populations a maximumfrequency of $3 \%$ is found (13), while in Eurasian and Indianpopulations the frequency is less than 5\% (14). In populations withMongoloid traits (such as the Chinese, Eskimo and American Indians), reports have noted that the RE occurs with a frequency that ranges from5\% to more than $30 \%$ (14 18). Because of its high frequency in thesepopulations, the RE is considered to be a normal morphological variant(eumorphic root morphology). In Caucasians the RE is not very commonand, with a maximum frequency of 3.4 to $4.2 \%(21,22)$, is consideredto be an unusual or dysmorphic root morphology. (1-8)

This case report presents the endodontic treatment of a Radix Entomolaris in mandibular first molar with four root canals.

\section{CASE REPORT}

A 16 year-old male patient presented with a complaint of pain in the posterior right mandibular region for the past two weeks. He gave a history of intermittent pain in the same region for the past three months. His past medical history was found to be non-contributory. Clinical examination revealed a carious right mandibular first molar. The clinical and radiographic findings led to a diagnosis of chronic irreversible pulpitis of the right mandibular first molar, necessitating endodontic therapy.

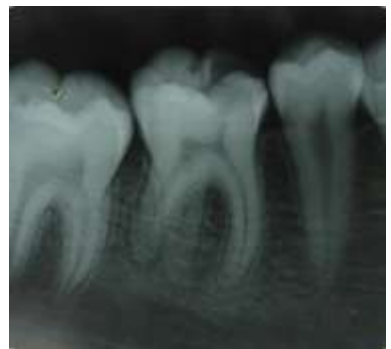

Fig 1: Preoperative radiograph with $20^{\circ}$ mesial angulation showing the extra distal root 
Radiographic evaluation of the involved tooth revealed normal configuration of single mesial root with two mesial canals and also the presence of a supernumerary root in addition to a mesial and a distal root. The extra root originated from the distolingual part of the tooth and appeared to be relatively straight (Fig 1). The right inferior alveolar nerve was anesthetized using 2\% Lignocaine with 1:80,000 adrenaline (Lignox, Indoco Remedies Ltd, India). The tooth was isolated using a rubber dam and an endodontic access cavity was established. Careful examination of access cavity revealed four distinct orifices, two located mesially (mesiobuccaland mesiolingual) and two distally (distobuccal and distolingual). Multiple, working-length radiographs taken at different angulations with one file placed in each of the two mesial and two distal orifices revealed the presence of four distinct canals. The working length radiograph confirmed the presence of 4 distinct orifices and 4 apical terminations (Fig 2). Cleaning and shaping was performed using a crown down preparation with hero shaper files (Micro mega, France) nickel-titanium rotary instruments (Maillefer, Dentsply, Ballaigues, Switzerland) under abundant irrigation with $5.25 \%$ sodium hypochlorite solution and EDTA (Glyde, Maillefer, Dentsply, Ballaigues, Switzerland) in a $5 \mathrm{~mL}$ syringe. The root canals were dried with paper points (Maillefer, Dentsply, Ballaigues, Switzerland). The master cone radiograph was taken (Fig 3) and obturation was done with cold, laterally condensed gutta-percha (Maillefer, Dentsply, Ballaigues, Switzerland) andAH-Plus sealer. Postobturation radiograph (Fig 4) reveals 2 mesial canals, and 2 distal canals (Vertucci type 1).

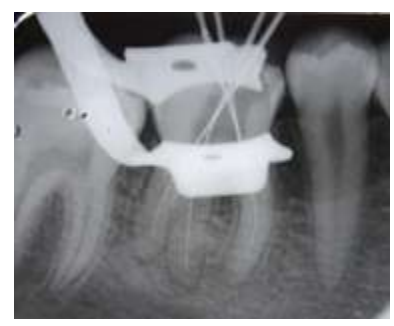

Fig 2: Working length radiograph with $20^{\circ}$ mesial angulation

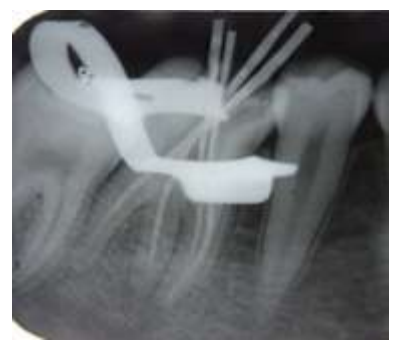

Fig 3: Master cone radiograph

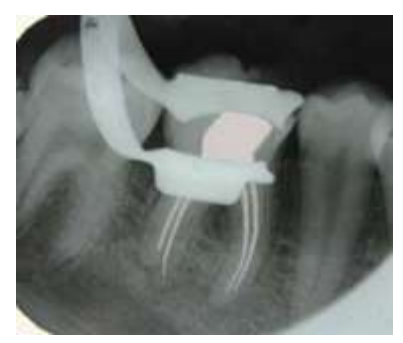

Fig 4: Post-obturation radiograph showing obturated mandibular first molar with radix entomolaris

\section{Discussion}


The presence of an RE has clinical implications in endodontictreatment. An accurate diagnosis of these supernumerary rootscan avoid complications or a 'missed canal' during root canal treatment (1).Endodontic success in the presence of RE dependson its diagnosis, anatomy or morphology, canalconfiguration and clinical approach employed.

Morphology of the RE and RP: The RE is located distolingually, with its coronal third completely or partially fixed to the distal root.The dimensions of RE root may vary from a short conical extension to a 'mature' root with normal length and root canal. (1-3)

RE can be classified into four different types depending on the location of its cervical part (15).

i. Type A: the RE is located lingually to the distal root complex which has two cone-shaped macrostructures.

ii. Type B: the RE is located lingually to the distal root complex which has one cone-shaped macrostructures.

iii. Type C: the RE is located lingually to the mesial root complex.

iv. Type AC: the RE is located lingually between the mesial and distal root complexes.

Each type has a sub classification to allow for the identification of separate or no separate RE.

An alternative classification of RE by De Moor et al describes the curvature of the root or the root canal (16).

i. Type 1: a straight root or root canal.

ii. $\quad$ Type 2: a curved coronal third which becomes straighter in the middle and apical third.

iii. Type 3: an initial curve in the coronal third with a second buccally oriented curve which begins in the middle or apical third.

Clinically, apart from the awareness about the possibleexistence and the racial prevalence of RE, factors suchas an extra cusp, prominent distolingual lobe, cervicalconvexity, and complex external contour of the furcationcan indicate the presence of an RE. Radiographically,double periodontal ligament images or an unclear view oroutline of the distal root contour or the root canal canhint the presence of an RE. However, this requiresa thorough inspection of the preoperative radiograph.It is mentioned that the radiographs were successful while identifying additional rootsbut superimposition of the distal roots can be a limitingfactor. An angled radiograph $\left(25-30^{\circ}\right)$ can be moreuseful in this regard and it is said that a mesial angledradiograph is better than a distal angled radiograph forRE detection.(13-20)

Diagnostic measures such as multiple, preoperative radiographs, examination of the pulp chamber floor with a sharp explorer, troughing of the grooves with ultrasonic tips, staining the chamber floor with $1 \%$ methylene blue dye, performing the sodium hypochlorite "champagne bubble test," and visualizing canal bleeding points are all important aids in locating root canal orifices (3). A DG 16 endodontic explorer used as a pathfinder determines the angle at which the canals depart from the main chamber. The search for an extra orifice is also aided by theuse of magnifying loupes and fibre-optic transillumination to locate the developmental line between the mesiobuccal and mesiolingual orifices. The detection of root canal orifices may be influenced by an anatomical configuration of the root canal system. Also, a better understanding of the root canal anatomy would make it easier to locate canal orifices under magnification, even if the canal anatomy was complicated (19).

Based on the literature, the majority of radices entomolarisare curved. In some cases there is an additional curvestarting from the middle of the root or in the apical third.Hence using precurved files, to establish a smooth glide pathto the apical segment and Nickel-Titanium rotary files forcleaning and shaping, is the desired option (1-4)

\section{Conclusion}

The primary diagnosis of a radix entomolaris before root canal treatment is important to facilitate the endodontic procedure, and to avoid 'missed' canals. Preoperative periapical radiographs exposed at two different horizontal angles, and advanced tools such as CBCT, are required to identify these additional roots. Knowledge of the location of the additional root and its root canal orifice will result in a modified opening cavity with extension to the distolingual. In the case of an RE the conventional triangular opening cavity must be modified to a trapezoidal form in order to better locate and access the distolingually located orifice of the additional root.

\section{References}


[1]. Calberson FL, De Moor RJ, Deroose CA. The radix entomolaris and paramolaris: clinical approach in endodontics. Journal of Endodontics2007;33(1):58-63.

[2]. Barbizam JV, Ribeiro RG, TanomaruFilho M. Unusual anatomy of permanent maxillary molars. J Endod 2004 Sep;30(9):668-71.

[3]. Vertucci FJ. Root canal anatomy of the human permanent teeth. Oral Surgery, Oral Medicine, Oral Pathology1984;58(5):589-99.

[4]. R. J. G. De Moor, C. A. J. G. Deroose, and F. L. G. Calberson, "The radix entomolarisin mandibular first molars: an endodontic challenge,” International Endodontic Journal, vol. 37, no. 11, pp. 789-799, 2004.

[5]. Sperber GH, Moreau JL. Study of the number of roots and canals in Senegalese first permanent mandibular molars. IntEndod J 1998;31:112-6.

[6]. Tratman EK. Three-rooted lower molars in man and their racial distribution. Br Dent J 1938;64:264 -74.

[7]. Pedersen PO. The East Greenland Eskimo dentition. Numerical variations and anatomy. A contribution to comparative ethnic odontography. Copenhagen: MeddeleseromGronland 1949;104:140-4.

[8]. Turner CG 2nd. Three-rooted mandibular first permanent molars and the question of Am Indian origins. Am J PhysAnthropol 1971;34:229-41.

[9]. K. Attam, R. R. Nawal, S. Utneja, and S. Talwar, "Radix Entomolarisin MandibularFirst Molars in Indian Population: A Review and Case Reports" Hindawi Case reports in Dentistry,vol. 2012 pp. 1-7

[10]. S. C. Yew and K. Chan, "A retrospective study of endodontically treated mandibular first molars in a Chinese population,"Journal of Endodontics, vol. 19, no. 9, pp. 471-473, 1993.

[11]. P. Krasner and H. J. Rankow, “Anatomy of the pulp-chamber floor,” Journal of Endodontics, vol. 30, no. 1, pp. 5-16, 2004.

[12]. Ferraz JA, Pecora JD. Three-rooted mandibular molars in patients of Mongolian, Caucasian and Negro origin. Braz Dent J 1993;3:113-7.

[13]. Vivekananda Pai AR, Jain R, Colaco AS. Detection and endodontic management of radix entomolaris: Report of case series. Saudi Endod J 2014;4:77-82.

[14]. Garg AK, Tewari RK, Kumar A, Hashmi SH, Agrawal N, Mishra SK. Prevalence of three-rooted mandibular permanent first molars among the Indian Population. J Endod 2010;36:1302-6.

[15]. de Almeida-Gomes F, de Sousa BC, dos Santos RA. Unusual anatomy of mandibular premolars. AustEndod J 2006 Apr;32(1):43-5.

[16]. Carlsen O, Alexandersen V. Radix entomolaris: identification and morphology. Scand J Dent Res 1990 Oct;98(5):363-73.

[17]. Walker T, Quakenbush LE. Three rooted lower first permanent molars in Hong Kong Chinese. Br Dent J 1985;159:298 -9.

[18]. W. Somogyi-Csizmazia and A. J. Simons, "Three-rooted mandibular first permanent molars in Alberta Indian children," Journal of the Canadian Dental Association, vol. 37, no.3, pp. 105-106, 1971.

[19]. Yoshioka T, Kobayashi C, Suda H. Detection rate of root canal orifices with a microscope. J Endod 2002 Jun;28(6):452-3.

[20]. Saunders WP, Saunders EM. Conventional endodontics and the operating microscope. Dent Clin North Am 1997 Jul;41(3):415-28.

[21]. Segura-Egea JJ, Jimenez-Pinzon A, Rios-Santos JV. Endodontic therapy in a 3-rooted mandibular first molar: Importance of a thorough radiographical examination. J Can Dent Assoc 2002;68:541-4.

[22]. Song JS, Choi HJ, Jung IY, Jung HS, Kim SO. The prevalence and morphologic classification of distolingual roots in the mandibular molars in a Korean population. J Endod 2010;36:653-7. 